OPEN ACCESS

Edited by:

John Pintar

Rutgers, The State University of

New Jersey, United States

Reviewed by:

Andreas Hoeflich,

Leibniz Institute for Farm Animal

Biology, Germany

Wendie Cohick

Rutgers, The State University of

New Jersey, United States

*Correspondence:

Danielle M. Robertson

danielle.robertson@

utsouthwestern.edu

tThese authors share first authorship

Specialty section:

This article was submitted to

Molecular and Structural

Endocrinology,

a section of the journal

Frontiers in Endocrinology

Received: 01 October 2019

Accepted: 14 January 2020

Published: 03 March 2020

Citation:

Stuard WL, Titone $R$ and

Robertson DM (2020) The IGF/Insulin-IGFBP Axis in Corneal Development, Wound Healing, and Disease. Front. Endocrinol. 11:24. doi: 10.3389/fendo.2020.00024

\section{The IGF/Insulin-IGFBP Axis in Corneal Development, Wound Healing, and Disease}

\author{
Whitney L. Stuard ${ }^{\dagger}$, Rossella Titone ${ }^{\dagger}$ and Danielle M. Robertson * \\ Department of Ophthalmology, UT Southwestern Medical Center, Dallas, TX, United States
}

The insulin-like growth factor (IGF) family plays key roles in growth and development. In the cornea, IGF family members have been implicated in proliferation, differentiation, and migration, critical events that maintain a smooth refracting surface that is essential for vision. The IGF family is composed of multiple ligands, receptors, and ligand binding proteins. Expression of IGF type 1 receptor (IGF-1R), IGF type 2 receptor (IGF-2R), and insulin receptor (INSR) in the cornea has been well characterized, including the presence of the IGF-1R and INSR hybrid (Hybrid-R) in the corneal epithelium. Recent data also indicates that each of these receptors display unique intracellular localization. Thus, in addition to canonical ligand binding at the plasma membrane and the initiation of downstream signaling cascades, IGF-1R, INSR, and Hybrid-R also function to regulate mitochondrial stability and nuclear gene expression. IGF-1 and IGF-2, two of three principal ligands, are polypeptide growth factors that function in all cellular layers of the cornea. Unlike IGF-1 and IGF-2, the hormone insulin plays a unique role in the cornea, different from many other tissues in the body. In the corneal epithelium, insulin is not required for glucose uptake, due to constitutive activation of the glucose transporter, GLUT1. However, insulin is needed for the regulation of metabolism, circadian rhythm, autophagy, proliferation, and migration after wounding. There is conflicting evidence regarding expression of the six IGF-binding proteins (IGFBPs), which function primarily to sequester IGF ligands. Within the cornea, IGFBP-2 and IGFBP-3 have identified roles in tissue homeostasis. While IGFBP-3 regulates growth control and intracellular receptor localization in the corneal epithelium, both IGFBP-2 and IGFBP-3 function in corneal fibroblast differentiation and myofibroblast proliferation, key events in stromal wound healing. IGFBP-2 has also been linked to cellular overgrowth in pterygium. There is a clear role for IGF family members in regulating tissue homeostasis in the cornea. This review summarizes what is known regarding the function of IGF and related proteins in corneal development, during wound healing, and in the pathophysiology of disease. Finally, we highlight key areas of research that are in need of future study.

Keywords: cornea, IGF-1, IGF-1R, INSR, Hybrid-R, IGFBP-2, IGFBP-3 


\section{INTRODUCTION}

The cornea constitutes the outer covering of the eye and provides two thirds of the refractive power necessary for vision. It is composed of five layers including a stratified epithelium, Bowman's membrane, the collagenous stroma, Descemet's membrane, and the single cell layered endothelium (Figure 1A). Corneal innervation is supplied by the ophthalmic branch of the trigeminal nerve. While corneal innervation is described in detail elsewhere and is beyond the scope of this review, it is important to note that the corneal epithelium is the highest innervated structure in the body due to the high density of intraepithelial nerve terminals (Figure 1B) (4). This, along with the tight barrier function of the epithelium, plays a major role in protecting intraocular structures from the outside environment. In addition to protection, the cornea must maintain a smooth, transparent, and avascular appearance to allow for the passage of light. The avascular nature of the cornea is one of the cornea's many unique properties. Other important properties include the peripheral location of stem cells in the corneal limbus, the paired movement of daughter cells in the central cornea from the basal layer to the surface epithelium, the epithelium's exceedingly high glycogen content, and the precise organization of collagen lamellae that facilitates transparency.

Corneal wound healing is complex and requires a unique orchestration of events including resurfacing of the corneal epithelium, deposition of basement membrane, and regeneration of the extracellular matrix. At the level of the epithelium, immediately upon wounding, the basement membrane is disassembled and epithelial cells surrounding the wound margin migrate as a sheet to cover the wound. In the presence of an incisional wound, epithelial cells migrate down into the wounded stroma. Once the wounded area is fully covered by these flattened epithelial cells, proliferation of limbal and transient amplifying cells ensues, followed by migration, stratification, the re-establishment of junctional proteins, and the restoration of the basement membrane. When wounds extend beyond the epithelium into the corneal stroma, cytokines released by epithelial cells and present in tears transform the normally quiescent keratocytes into fibroblasts that migrate into the wounded area. This is followed by their sequential transformation into myofibroblasts, strong contractile cells that function to close the wound. Ultimately, over time, keratocytes repopulate, and remodel the extracellular matrix. However, abnormal extracellular matrix often persists, resulting in corneal fibrosis. Unlike the corneal epithelium, when damaged, the corneal endothelium does not proliferate to close a wound. Instead, endothelial cells flatten and spread, taking on a polymorphic appearance.

Many systemic diseases, such as diabetes, can dramatically alter the normal biology of the cornea, resulting in a thinned, dysplastic epithelium with damaged corneal nerves, and cell loss in the endothelial monolayer, the latter of which drives corneal swelling. Most notably, since diabetes can negatively impact all layers of the cornea, impaired corneal wound healing can present a major clinical problem that is often refractory to therapy. While greatly under-recognized, corneal complications occur in $40-$ $70 \%$ of diabetics (5). These complications, which range from mild
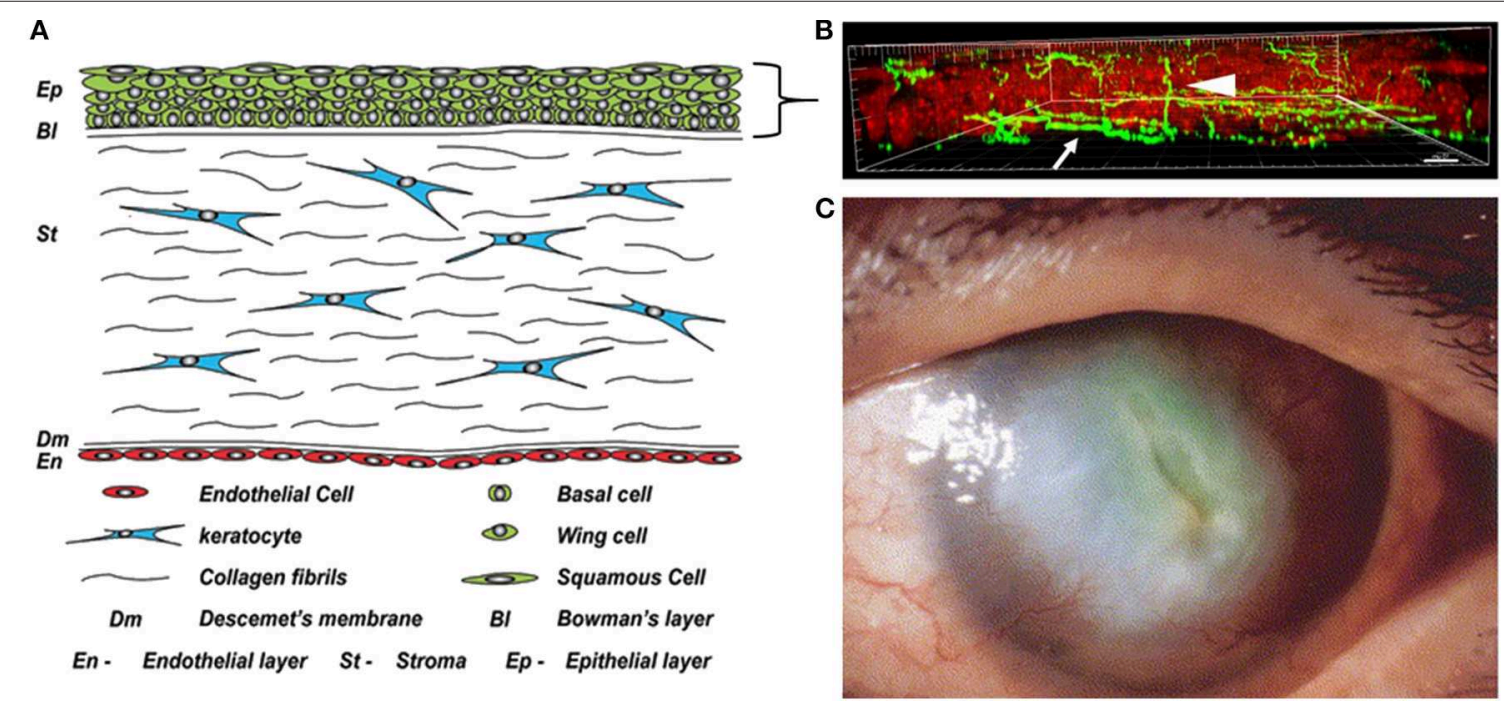

FIGURE 1 | The cornea in health and disease. (A) Anatomical schematic showing all five cell layers in the cornea. A five to seven stratified layer of epithelial cells (basal, wing, and squamous) composes the corneal epithelium. Keratocytes, normally quiescent cells, reside in the corneal stroma which consists of intertwining collagen fibrils. Finally, there is a single endothelial cell layer on the innermost layer of the cornea that faces the interior of the eye and is responsible for maintaining stromal hydration. Figure taken from Polisetti et al. (1). (B) Maximum intensity projection of nerves labeled with neuronal beta tubulin (green) in the mouse cornea in situ. Epithelial nuclei are counterstained with propidium iodide in red. Nerve fibers that run among the basal layer of the epithelium and just beneath it form the subbasal nerve plexus (arrow). Intra-terminal nerve fibers branch perpendicularly from the subbasal nerve plexus and run throughout the corneal epithelium to the surface of the eye (arrowhead). Figure taken from Cai et al. (2). (C) A cornea with diabetic keratopathy. Note the large central opacification and significant neovascularization. Image taken from Matsumoto et al. (3). 
to severe, can result in chronic and painful corneal complications, predispose the cornea to infection, and in advanced stages, lead to neurotrophic disease and blindness (Figure 1C) $(6,7)$. The importance of proper growth factor signaling in the normal and diabetic cornea is well-established. The focus of this review is to chronicle what is known about the localization and function of insulin-like growth factor (IGF) family members in the cornea and to highlight critical areas of investigation for future studies.

\section{THE IGF SYSTEM}

The insulin-like growth factor (IGF) system consists of two peptide ligands, IGF-1 and IGF-2, and the hormone insulin (Figure 2). These extracellular ligands activate the IGF Type 1 receptor (IGF-1R), the IGF type 2 receptor (IGF-2), and insulin receptor (INSR), all with varying affinities. The system is further regulated at the extracellular level by the presence of IGF-binding proteins (IGFBPs). There are six known IGFBPs. Historically, IGFBPs function to bind IGF-1 to prolong its half-life in circulation and to prevent IGF-1 induced activation of IGF-1R. This is mediated by proteolytic enzymes that function to cleave IGFBPs, thereby regulating the amount of bioavailable IGF-1. To date, two known proteases have been identified. They include the pregnancy-associated plasma proteins, PAPP-A, and PAPP$\mathrm{A} 2$, which are inhibited by the stanniocalcins $(8,9)$. In addition, the ligands, as well as binding proteins, have been shown to interact with IGF family receptors to exert unique effects that are cell and tissue dependent $(10,11)$. IGF-1 is well-known for its role in growth and development in physiologically healthy tissues (12). In the cornea, IGF-1R, IGF-2R, and INSR and their canonical ligands have been studied in the epithelium, stroma, and endothelium. As seen in other tissues, these works have demonstrated key biological roles for members of the IGF family in proliferation, homeostasis, differentiation, and wound healing.

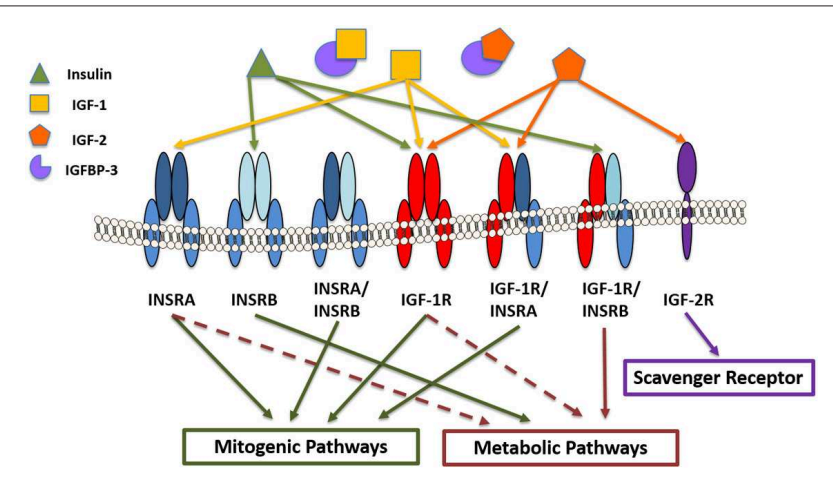

FIGURE 2 | IGF/insulin-IGFBP family members in the corneal epithelium. Receptors include insulin receptor A and B (INSRA and INSRB), IGF type 1 and type 2 receptors (IGF1-R and IGF-2R) and the hybrid receptors (INSRA/INSRB, IGF-1R/INSRA, and IGF1-R/INSRB). Insulin binds with higher affinity to INSRB and the hybrid receptor (IGF-1R/INSRB), predominantly activating metabolic pathways. IGF-1 and IGF-2 bind with higher affinity to IGF-1R and IGF-1R/INSRA, activating mitogenic signaling. IGF-2 also binds the scavenger receptor, IGF-2R. IGF binding protein-3 (IGFBP-3) sequesters IGF-1 and IGF-2, preventing them from binding to their cognate receptors.

\section{CHARACTERIZATION OF IGF-1R, IGF-2R, AND INSR IN THE HUMAN CORNEA}

Structurally, IGF-1R and INSR are transmembrane tetrameric glycoproteins comprised of two transmembrane beta subunits, each containing an intracellular tyrosine kinase domain, and two alpha subunits, each containing an extracellular ligand binding domain (13). In contrast to these receptors, IGF$2 \mathrm{R}$ is a monomeric transmembrane protein with 15 different extracellular domains (14). INSR differs from IGF-1R and IGF$2 \mathrm{R}$ in that it undergoes alternative splicing at exon 11 resulting in two different isoforms, INSRA and INSRB. Each isoform is thought to play distinct roles in development and metabolism. Expression of each also mediates affinity for insulin, kinase activity, and may contribute to the rate of internalization and receptor recycling.

INSR was first identified in the cornea by Naeser in the late 90's (15). In that work, he used immunohistochemical techniques to stain for INSR in donor human corneas with and without diabetic retinopathy. He found strong staining for INSR in the corneal epithelium, stromal keratocytes, and endothelium. Staining was unchanged in diabetes. Rocha and colleagues also used immunohistochemical techniques to show that INSR was indeed expressed in the corneal epithelium (16). In their study, INSR localized to the cytoplasm and plasma membrane primarily in the wing and superficial cell layers. Varied expression was evident in the basal and intermediate suprabasal cell layers. While not reported, INSR appeared to be expressed in nuclei of corneal epithelial cells. More recent work by our laboratory has used multiple complementary approaches to confirm expression of INSR in corneal epithelial cells and to define the intracellular localization of this protein (as discussed in greater detail later in this manuscript).

Nakamura first used ligand-binding assays to confirm the presence of IGF-1R in corneal epithelial cells and showed that IGF-1R had the greatest affinity for IGF-1, followed by IGF2 , and then insulin (17). As they did for INSR, Rocha also stained for the presence of IGF-1R in the corneal epithelium. Using an antibody that recognizes the extracellular alpha subunit of IGF-1R, they demonstrated robust staining at the plasma membrane throughout all epithelial layers. Subsequent studies by our laboratory have further characterized the expression and localization of IGF-1R in cultured corneal epithelia $(11,18,19)$. Using antibodies that recognize both the alpha and beta subunits of IGF-1R, we found that the full mature receptor localized to the nucleus of corneal epithelial cells. We confirmed this using subcellular fractionation and immunoblotting assays. We further found that IGF-1R interacts with E-cadherin at areas of cell-cell junctions (18). Interactions between IGF-1R and Ecadherin have been previously reported in tumor biology where they are thought to regulate tumor invasion and in Madin Darby canine kidney cells $(20,21)$. In this latter cell type, is was shown that binding to E-cadherin negatively regulated ligand-induced activation of IGF-1R (20). The significance of the interaction between IGF-1R and E-cadherin in the corneal epithelium is unknown. Consistent with a growth inhibitory role, we postulate that E-cadherin binding is necessary to attenuate 
IGF-1R activation and downstream signaling events that mediate proliferation and growth (18).

It has long been known that IGF-1R and INSR are highly homologous receptors, with 45-65\% homology in the amino acid sequence in the alpha subunit and $84 \%$ homology in the beta subunit (22). Due to this high level of homology, IGF-1R and INSR can hybridize to form an IGF-1R/INSR hybrid (HybridR). Hybrid-Rs can form with either INSR isoform. Hybrid-R is expressed in the corneal epithelium (19). Using dithiothreitol to cleave the class 1 disulfide bonds and separate IGF-1R alpha/beta subunits from INSR alpha/beta subunits following stimulation with IGF-1 or insulin, we confirmed that Hybrid-R is activated by IGF-1 and not insulin in corneal epithelial cells. Since INSR isoform A is predominantly activated by IGF-1 to promote IGF1 signaling, whereas INSR isoform B is predominantly activated by insulin and functions to attenuate IGF-1 signaling, our data suggest that in the corneal epithelium, Hybrid-R is composed of IGF-1R and INSR isoform A (19). This finding remains to be confirmed at a protein level.

Bohnsack and colleagues evaluated IGF-2R distribution in human, murine, and porcine corneas. In their study, they found that IGF-2R was present throughout all cell layers of the cornea (23). In murine and porcine models, expression was primarily localized to the basal epithelium. After wounding, they reported an 11-fold increase in IGF-2R in the stroma and epithelium. The increase in IGF-2R was associated with an increase in differentiation of fibroblasts to myofibroblasts, demonstrated by an increase in $\alpha$-SMA expression, which was subsequently blocked by shRNA knockdown of IGF-2R. Likewise, when keratocytes were cultured in serum free media and treated with TGF-beta to induce myofibroblast differentiation in vitro, there was a similar increase in IGF-2R expression in myofibroblasts, at the mRNA and protein level. Together, these findings suggest a potential role for IGF-2R in mediating fibroblast to myofibroblast transformation during wound healing.

\section{INTRACELLULAR IGF-1R, INSR, AND HYBRID-R}

More recently, non-canonical roles for IGF-1R and INSR have been suggested (24). In their seminal paper, Sehat et al. used human melanoma (DFB) and leiomysocarcoma (SKUT-1) cells along with human embryonic kidney cells (HEK 293) to first describe the nuclear localization of IGF-1R (25). Using a serum-based model, they demonstrated that serum starvation depletes IGF-1R from the nucleus and that treatment with IGF1 induced translocation of IGF-1R from the plasma membrane to the nucleus. They further showed that translocation to the nucleus was mediated by SUMOylation of IGF-1R by the SUMO modifier SUMO-1. It has since been shown that nuclear IGF$1 \mathrm{R}$ interacts with several different nuclear proteins and functions to regulate the cell cycle, DNA damage responses, invasion, and metastasis (26-29).

Like IGF-1R, studies have also reported that INSR localizes to the nucleus. In the late 70 's, Goldfine and colleagues were the first to demonstrate that insulin bound to isolated nuclei in vitro (30). They further showed that treatment of isolated nuclei with trypsin prevented insulin binding. The authors concluded that a hormone receptor modulated by insulin was present in rat liver nuclei. Just over a decade later, a second group refuted these earlier findings. In their study, Soler et al. used a combination of in vitro techniques to investigate a potential nuclear localized receptor (31). In contrast to the prior work, they concluded that once dissociated from INSR, the biologically intact and active hormone accumulated in the nucleus and associated with heterochromatin. Until recently, few studies have followed up on the potential for a nuclear-localized INSR. In rat hepatocytes, INSR has been shown to translocate to the nucleus where it regulates calcium signals and proliferation (32). Hancock and colleagues have also investigated the role of INSR in the nucleus of mouse liver cells (33). In their studies, they found that INSR directly associated with genome-wide promoters and regulates gene expression through interactions with RNA polymerase II.

Consistent with these studies, we have found that both IGF-1R and INSR localize to the nucleus of corneal epithelial cells (18). Unlike prior studies however, we have found that the nuclear localized receptor is Hybrid-R (19). We have further shown that Hybrid-R nuclear translocation occurs in response to growth factor withdrawal and is not induced by stimulation with IGF-1. Instead, expression and localization of each receptor is mediated by insulin (11). In the absence of insulin, expression of IGF$1 \mathrm{R}$ and INSR is upregulated and the receptors accumulate as Hybrid-R in the corneal epithelial cell nucleus. This is mediated through SUMOylation by the SUMO modifier SUMO2/3. The ability of insulin levels to regulate Hybrid-R nuclear translocation is due to its ability to regulate extracellular levels of IGFBP-3. Studies in our laboratory which decrease expression of IGFPB-3 using siRNA knockdown followed by the addition of exogenous recombinant human IGFBP-3 not only demonstrate robust translocation to the nucleus, but also drive receptor accumulation in the insoluble nuclear fraction, indicating association with DNA (11). While we have been unable to detect the presence of IGF-1R alone in the nucleus, we have not yet ruled out the presence of INSR not complexed with IGF-1R.

Our more recent studies on the function of intracellular IGF1R, INSR, and Hybrid-R have led to the novel observation that INSR and IGF-1R are present in mitochondria (34). Using mitochondrial fractionation assays, we have confirmed that IGF$1 \mathrm{R}$ and INSR localize to mitochondria and that expression of both accumulates during stress induced by growth factor withdrawal. Using reciprocal immunoprecipitation, we have further found that INSR and IGF-1R bind the voltage gated anion channel, VDAC1. Importantly, when we disrupt the interaction between INSR and VDAC1 using INSR knockdown, we see robust mitochondrial ring/donut shaped fragmentation. This finding indicates that the novel interaction between INSR and VDAC1 is important for mediating mitochondrial stability (34).

\section{INSULIN AND GLUCOSE UPTAKE}

Insulin is a peptide hormone that functions to mediate metabolic effects in addition to growth and proliferation. Structurally, 
bioactive insulin presents in humans as a monomer consisting of two chains: an A-chain and B-chain, joined by disulfide bonds $(35,36)$. Insulin is produced by beta cells in the pancreas, where it is stored and secreted in response to high levels of blood glucose (37). In most cell types and tissues, insulin is required for glucose uptake. In tissues such as skeletal muscle, adipose tissue, and lungs, insulin binds INSR and promotes the uptake of glucose from circulation through glucose transporter-4 (GLUT4) (38). In certain tissues however, such as the corneal epithelium, glucose uptake is insulin independent, meaning that corneal epithelial cells do not require insulin for glucose uptake (Figures $\mathbf{3 A}, \mathbf{B}$ ) $(39,40)$. Instead, glucose uptake is mediated by a constitutively active glucose transporter, GLUT1 (41). This allows for the continuous passage of glucose into cells (39). In conditions where the metabolic demand is increased, such as following a wound, the corneal epithelium responds by increasing the number of GLUT1 transporters in order to provide sufficient energy for proliferation, migration, and survival (42).
Using a rat corneal wound model, Takahashi and colleagues found that levels of both GLUT1 mRNA and protein were increased in the corneal epithelium as early as $4 \mathrm{~h}$ after wounding, peaking at 2 days post-injury (43). They hypothesized that the increase in GLUT1 was necessary to facilitate increased glucose uptake and provide fuel to promote wound healing. In a subsequent study by the same group, they used streptozotocin, a drug known to kill insulin-producing pancreatic beta cells, to induce Type 1 diabetes mellitus. They then examined GLUT1 expression before and after wound healing. They found that in response to the wound, GLUT1 was similarly increased in both diabetic and control groups compared to the non-wounded controls. However, there was no difference in receptor expression prior to wounding between diabetic and non-diabetic animals. Together, their findings indicated that GLUT1 expression had no impact on delayed corneal wound healing in diabetes. This work is in agreement with early studies done by Kumagai et al. that also failed to show any
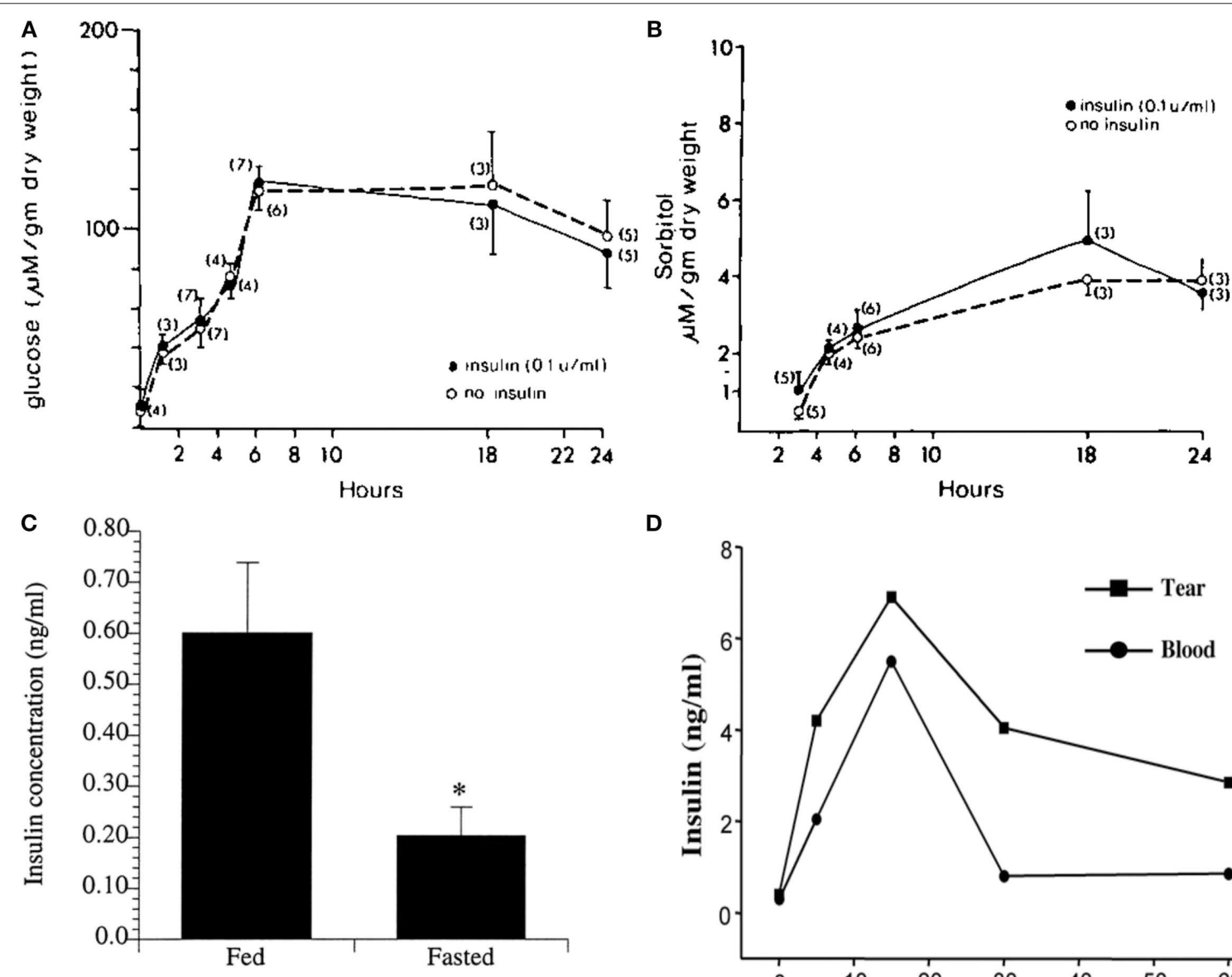

D

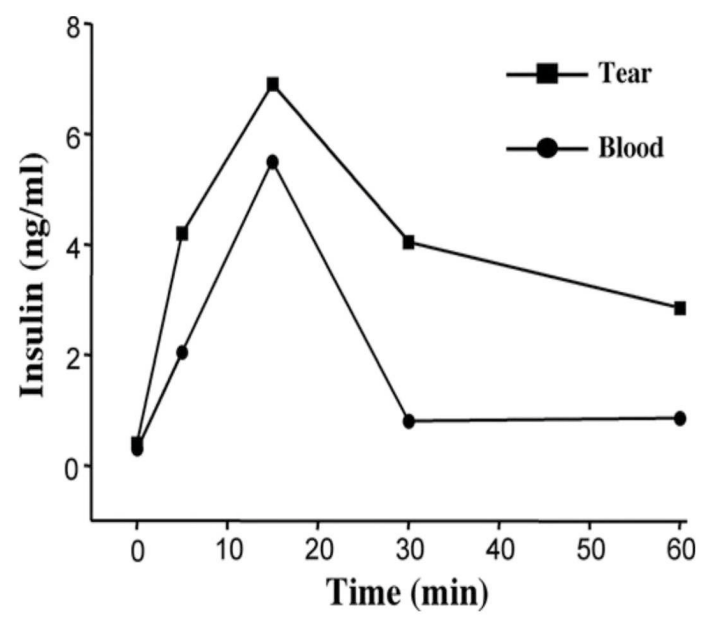

FIGURE 3 | Corneal epithelial cells are "insulin insensitive" and do not require insulin for glucose uptake. (A) Glucose content (micromoles per gram \pm SEM) of corneal epithelial cells after incubation with $35 \mathrm{mM}$ glucose in TC-199 with and without insulin. (B) Corneal epithelial cell sorbitol (micromoles per gram \pm SEM) content after incubation with $35 \mathrm{mM}$ glucose in TC-199 with and without insulin. A\&B adapted from Friend et al. (39). (C) Radioimmunoassay (RIA) measurement of mean insulin levels present in tears of fasted vs. fed human subjects, $P<0.05$. Adapted from Rocha et al. (16). ${ }^{*} P<0.05$. (D) Insulin levels in tears measured by RIA over time after systemic administration of glucose (1 g/kg body wt) in rats. Adapted from Cunha et al. (40). 
differences in GLUT1 expression in the diabetic vs. non-diabetic human cornea (44).

In addition to its role in glucose homeostasis, insulin has broader cellular functions including regulation of cell metabolism, autophagy, apoptosis, growth, and proliferation (45). While insulin is not required for glucose uptake, insulin and its receptors are present in the human cornea and tear film (16). Moreover, insulin levels are increased in tears in fed individuals compared to fasted (Figure 3C). Similar to humans, insulin is increased in the rat tear film following a single bolus of glucose administered intravenously (Figure 3D) (40). It is unknown whether tear derived insulin is taken up by terminally differentiated surface epithelial cells or is able to somehow cross the tight epithelial barrier, the latter of which is unlikely. Thus, the functional significance of insulin in tear fluid is unknown.

\section{INSULIN AND METABOLISM IN CORNEAL EPITHELIAL CELLS}

Cunha and colleagues were the first to confirm a role for insulin in corneal metabolism (40). Studies in our laboratory have sought to further this work and define the mechanism by which insulin regulates cellular metabolism and growth in the corneal epithelium. To accomplish this, we first investigated the role of insulin in regulating cell cycle control in human corneal epithelial cells. After $48 \mathrm{~h}$ of growth factor withdrawal, corneal epithelial cells arrested in G0/G1. This arrest was partially restored following treatment with insulin for the final $24 \mathrm{~h}$ (11). In that same study, we determined the metabolic phenotype of corneal epithelial cells. We again found that insulin was able to partially restore mitochondrial respiration. This was not due to a shift in glycolysis however, but an increase in mitochondrial respiration (11). To further investigate these findings, we tested the effect of co-treatment with insulin when cells were cultured in basal conditions (no growth factors). Interestingly, we found that corneal epithelial cells undergo a metabolic fuel switch between 24 and $48 \mathrm{~h}$ of culture during growth factor withdrawal. In the first $24 \mathrm{~h}$, metabolic activity is driven principally by mitochondrial respiration, whereas in the last $24 \mathrm{~h}$, glycolysis is upregulated to account for a sudden decrease in respiration. In both conditions, insulin was able to maintain both respiration and glycolysis. Consistent with the measured drop in respiration at $48 \mathrm{~h}$, fluorescent imaging showed that mitochondria were largely depolarized. Similar to its effect on respiration, co-treatment with insulin also blocked the loss of depolarization in these cells (Figure 4) (34). Together, these findings support that insulin promotes mitochondrial respiration in corneal epithelial cells by maintaining mitochondrial polarization.

Insulin is known to activate $\mathrm{PI} 3 \mathrm{~K} / \mathrm{Akt} / \mathrm{mTOR}$ signaling by first binding INSR or IGF-1R at the plasma membrane and then activating downstream cell survival pathways (46). In our laboratory, we showed that insulin regulates phosphorylation of Akt at ser473 in human corneal epithelial cells (11). Activation of this kinase cascade led to an increase in phosphorylation of GS3K $\beta$ at the inhibitory residue, ser9. Since GS3K $\beta$ is a key regulator of cell cycle control, mitochondrial function and apoptosis, and the autophagy inhibitor mTOR, phosphorylation of this residue leads to activation of mTOR and a block in autophagy $(47,48)$. Autophagy or macroautophagy is a cannibalistic mechanism used by cells to recycle damaged components and debris (49). Selective autophagy represents organelle-specific autophagy. Mitophagy, which is a key mitochondrial quality control mechanism, is the process whereby mitochondria are targeted to autophagosomes (50). In the presence of mitochondrial depolarization, as shown in our growth factor withdrawal model, PTEN-induced kinase 1 (PINK1) becomes stabilized in the mitochondria. PINK1 is a well-studied mitophagy marker that functions to recruit Parkin to the mitochondria. Parkin in turn ubiquitinates mitochondrial proteins, triggering recognition by the autophagosome for subsequent engulfment by the autophagolysosome. Similar to autophagy, insulin blocks all autophagic flux, including mitophagy, in corneal epithelial cells (34). In contrast to this, in breast cancer cells, IGF-1 has been shown to induce mitophagy through activation of the mitophagy receptor BNIP3 (51). Whether IGF-1 is able to activate macro- or selective autophagy in corneal epithelial cells is still unknown, but represents an exciting avenue for study.
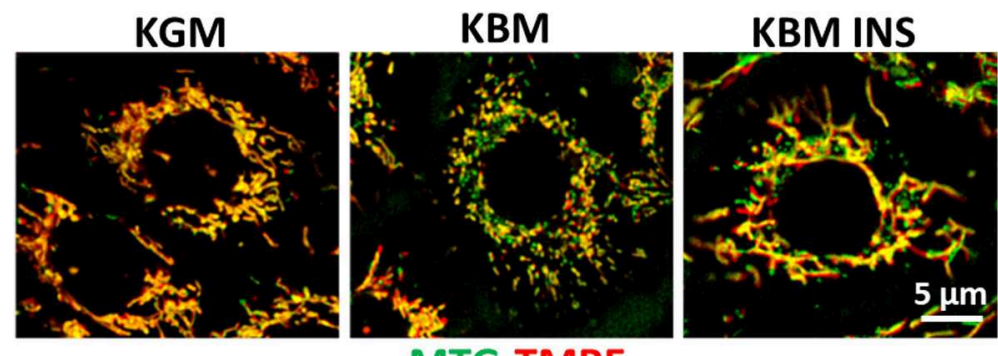

MTG-TMRE

FIGURE 4 | Insulin blocks loss of mitochondrial depolarization. hTCEpi cells were cultured for $48 \mathrm{~h}$ in KGM or KBM with or without $5 \mu \mathrm{g} / \mathrm{ml}$ of insulin. Mitochondria were stained with MitoTracker green (MTG, green), a marker of mitochondrial morphology, and TMRE (red), a marker for polarized mitochondria. Culture in basal media without growth factor supplements resulted in mitochondrial depolarization and fragmentation. Concurrent treatment with insulin blocked depolarization and stimulated mitochondrial elongation. KGM, keratinocyte growth media; KBM, keratinocyte basal media; INS, insulin; hTCEpi cells, human telomerized corneal epithelial cells. Scale bar: $5 \mu \mathrm{m}$. Adapted from Titone et al. (34). 


\section{INSULIN AND THE DIABETIC CORNEA}

Several studies have described the effects of high glucose on corneal epithelial homeostasis through modulation of cell signaling, cell proliferation, and wound healing $(7,52-54)$. Clinically, these changes are manifested in the diabetic cornea in the form of superficial punctate keratitis, alterations in epithelial barrier function, recurrent epithelial erosions due to the presence of an abnormal basement membrane, persistent epithelial defects, and refractory wounds despite treatment $(7,54)$. In addition to cellular changes, the loss of corneal nerves drives a reduction in corneal sensitivity and this leads to epithelial thinning and reduced tear secretion. The latter of which underlies a cause of dry eye (53). The mechanisms leading to development of corneal complications are multifactorial and are due in part, to abnormal growth factor signaling and the accumulation of reactive oxygen species (53).

Due to the ability of insulin to promote proliferation in cell culture, topical insulin has been proposed as a treatment modality to promote corneal epithelial wound healing (Table 1). In their study, Zagon et al. used streptozotocin to induce diabetes in Sprague-Dawley rats (55). In this model, they made a $5 \mathrm{~mm}$ corneal wound, followed by treatment with topical insulin four times a day for 7 days. Compared to the vehicle control, topical insulin promoted epithelial resurfacing and an increase in proliferation of basal epithelial cells. Interestingly, treatment with topical insulin also restored corneal sensitivity to normal levels, suggesting that insulin also promoted corneal re-innervation.
Bastion later reported on the results of a retrospective study evaluating the effects of topical insulin on healing epithelial defects in human diabetic patients who were subject to epithelial debridement while undergoing vitreoretinal surgery (56). Fifteen eyes of 14 patients (one patient had bilateral epithelial defects) were divided into one of three groups, diabetics who received topical insulin, diabetics who did not receive topical insulin, and non-diabetics who received topical insulin. In all cases where insulin was administered, re-epithelialization was accelerated compared to non-insulin controls. There were no cases of toxicity or adverse events reported. However, only five patients were evaluated per group. Fai et al. reported on the results of a much larger study (57). Over a 2 year period, all patients with epithelial defects following vitreoretinal surgery were recruited and randomized into one of four groups: $0.5,1.0$, or 2 units of insulin or a saline control. Patients receiving 0.5 units of topical insulin four times a day demonstrated the best efficacy, with clinical effects being lost at the highest dosage.

More recently, Wang and colleagues reported on a small case series of six human subjects with refractory corneal ulcers (59). Patients ranged in age from 2 to 73 years and all presented to clinic with non-healing neurotrophic corneal ulcers. Patients all had past ocular histories that included a battery of therapeutic treatments and surgical procedures that resulted in incomplete healing. In all six cases, one unit of insulin was administered at a frequency of 2-3 times a day and all patients resolved over a period of $7-25$ days.

TABLE 1 | Published studies evaluating the role of IGF family ligands in the cornea.

$\begin{array}{lll}\text { Molecular } \quad \text { Wound repair } & \text { References } \\ \text { pathway } & \end{array}$

Insulin

Promotes epithelial resurfacing and proliferation in rodent model.

Enhances healing rates in patients with epithelial defects following vitrectomy.

Dosed at 0.5 units QID was effective on healing epithelial defects post vitrectomy in diabetic patients without drug toxicity.

Aides in wound repair through restoration of circadian rhythm in the corneal epithelium.

Promotes healing in neurotrophic corneal ulcers.

IGF-1 Used with substance P accelerates corneal epithelial cell migration.

Used with the substance P-derived peptide (FGML) increases epithelial migration.

Used with Substance $\mathrm{P}$ promotes epithelial wound healing in an in vivo rabbit model.

Used with substance $\mathrm{P}$ promotes epithelial attachment to fibronectin and Type VI collagen in a rabbit model.

Identified the minimum sequence of substance $P$ necessary for a synergistic wound healing effect. 


\section{INSULIN AND CIRCADIAN RHYTHM}

In rodent models, the proliferation of basal epithelial cells in the central cornea and epithelial regeneration following a wound are regulated in part by circadian rhythms (74-77). In addition, oscillations in the expression of core circadian genes, including Clock and Bmal1, have also been reported (74). While diabetes and other metabolic disorders are known to disrupt normal circadian rhythms, Song and colleagues investigated the impact of diabetes on circadian rhythms in the corneal epithelium using a Type 1 streptozotocin mouse model (58). After 2 weeks of disease, there was a significant change in key clock genes, a reduction in basal cell proliferation, and an increase in leukocyte infiltration in the limbal region. These effects were partially restored by the administration of systemic insulin. Since these studies were performed so early on following onset of diabetes, the circadian effects could be measured without the corresponding effects from loss of the subbasal nerve plexus. Thus, it is likely that alterations in the circadian rhythm reflect an early change in diabetes that contributes to disruption of normal homeostasis.

\section{INSULIN AND THE CORNEAL ENDOTHELIUM}

The corneal endothelium is a single cell layer on the posterior aspect of the cornea that is flush with the aqueous humor. Function of the corneal endothelium is critical to maintain optimal hydration and stromal transparency. The role of IGF and insulin in the corneal endothelium has not been well-studied. In the bovine corneal endothelium, IGF- $1 \mathrm{R}$ is $\sim 25$ times more highly expressed than INSR (78). This finding would explain why stimulation of bovine corneal endothelial monolayers with IGF-1 promoted DNA synthesis. While low levels of IGF-1 are able to not only stimulate DNA synthesis, they also induce an upregulation of the proto-oncogene c-fos. Unlike IGF-1, a high concentration of insulin is required to have a similar effect. This is likely due to the ability of insulin to activate IGF-1R at high levels.

Insulin has been shown to play a key role in the regulation of the Na/K-ATPase pump. The Na/K-ATPase pump functions to maintain water balance in the corneal stroma. In diabetes, endothelial cells are highly subject to damage during intraocular surgery and often display a certain degree of pleomorphism even in the absence of surgery (79). Corneal thickening in diabetes is thus due to improper pump function secondary to loss of corneal endothelial cells. In support of this, studies using an alloxan-induced diabetic rabbit model showed that a decrease in NA/K-ATPase activity was associated with an increase in corneal thickness and poor hydration control (80). Like glucose, insulin is present in the aqueous at a much lower concentration than serum. In alloxan-induced diabetes, levels of insulin in the aqueous are further depleted. To determine whether alterations in aqueous insulin levels in diabetes could account for the changes in pump function, Hatou et al. investigated the effect of insulin on $\mathrm{Na} / \mathrm{K}$-ATPase activity in mouse corneal endothelial cells in vitro (81). Importantly, they found that administration of insulin $(0.01-10 \mu \mathrm{M})$ to an endothelial monolayer increased the activity of the $\mathrm{Na} / \mathrm{K}$-ATPase pump through activation of protein kinase $\mathrm{C}$ in a concentration dependent manner (82). It is important to note that these changes were transient in nature. Thus, a chronic insult from either no insulin in Type 1 diabetes or reduced signaling due to insulin resistance, such as that seen in Type 2 diabetes, may contribute to the pathophysiology of diabetes induced corneal endothelial damage.

\section{IGFS IN WOUND HEALING AND REPAIR}

IGF-1 and -2 are homologous peptides that modulate cellular proliferation and differentiation throughout the body (83). Activation of their cognate receptors triggers autophosphorylation of their intracellular kinase domain, leading to downstream activation of the Janus kinase/signal transducers and activators of transcription (JAK/STAT), phosphoinositide 3-kinase (PI3K), and mitogen-activated protein kinase (MAPK) pathways $(22,84,85)$. IGF-1 has been well-studied for its important role in cellular migration and proliferation in non-ocular tissues (86). In all three cell layers of the cornea, IGF has been shown to have critical regulatory functions that preserve homeostasis and promote wound repair. In the corneal epithelium, IGF-1 promotes proliferation. This occurs through activation of Hybrid- $\mathrm{R}$ and subsequent phosphorylation of Akt (19). IGF-1 was also shown by Lee and colleagues to induce corneal epithelial cell migration and increased expression of Lamin-5 and $\beta 1$-integrin. These effects were mediated through the PI3K/AKT pathway (68).

Lastly, some data exists to support that IGF-1 also contributes to the differentiation of limbal stem cells into corneal epithelial cells. In their study, Trosan et al. found that after central epithelial debridement in the mouse cornea, IGF-1 and IGF-2 secretion is increased in corneal epithelial cells, while IGF-1R expression was increased in the limbus (71). Interestingly, the increase in IGF-1R expression in the limbus was driven by IGF-1 and promoted differentiation of limbal epithelial cells, evidenced by an upregulation of the cytokeratin K12. A subsequent study with a similar experimental design showed the same effect for IGF-2 (73).

\section{IGF AND SUBSTANCE P}

Much of what is known regarding the function of IGF-1 in corneal epithelial wound healing is focused on the interactive role of IGF-1 with the neuropeptide, substance P (Table 1). In their in vitro studies, Nishida and colleagues showed that IGF-1 administered at a concentration of $10 \mathrm{ng} / \mathrm{ml}$ accelerated corneal epithelial cell migration across a wounded rabbit corneal stroma ex vivo when used in conjunction with 25 or $50 \mu \mathrm{g} / \mathrm{ml}$ substance P (60). Likewise, IGF-1 together with substance P, promoted corneal epithelial attachment to fibronectin and Type IV collagen. They further showed that this effect was not due to changes in ligand binding sites for IGF-1, but was mediated by interactions between substance $\mathrm{P}$ and the Tachykinin receptor, Nrk1 $(17,87)$. These findings were confirmed in a rabbit model 
subject to epithelial debridement using N-heptyl alcohol (62). Additional work by this group induced corneal neuropathy in a rat model by thermocoagulating the ophthalmic nerve that branches from the trigeminal ganglion (64). Using this model they showed that treatment of corneal epithelial wounds with substance P and IGF-1 improves barrier function in the corneal epithelium by promoting wound healing. Subsequent publications by this same group have further elaborated on these key findings and identified the specific amino acid sequences for both substance $\mathrm{P}$ and IGF-1 that are responsible for mediating these effects $(63,65-67,69,70,72)$.

\section{IGF-1 IN TEAR FLUID}

IGF-1 is present in tear fluid, although at very low levels $(88,89)$. In normal healthy conditions, the ratio of IGF-1 to IGFBP3 is not sufficient to blunt the effects of IGF-1. However, in human diabetic tear fluid, the ratio of IGF-1 to IGFBP-3 is significantly reduced (89). Since IGF-1 binds IGFBP-3 with a greater affinity than IGF-1R, the shift in the IGF-1 to IGFBP-3 ratio is sufficient to sequester IGF-1 and inhibit the ability of IGF1 to induce phosphorylation of IGF-1R or Hybrid-R (89). The inability of IGF-1 to promote proliferation in the diabetic corneal epithelium may contribute to delayed wound healing. IGF-1 and IGF-2 have both been shown to be upregulated during corneal wound healing. It is not clear whether either of these proteins are upregulated in the diabetic eye.

\section{IGF-1 AND STROMAL KERATOCYTES}

The effects of IGF-1 are not restricted to the corneal epithelium, but also play an important regenerative role in the stroma. Corneal keratocytes, the primary cell type in the stroma, are essential for not only maintaining stromal structure but also form an interconnected, communication network within the cornea. It has been shown that IGFs play an important role in regulating formation of this network. Using the IGF-1R inhibitor, picropodophyllin (PPP), Berthaut found that the addition of IGF-1 in concert with PPP blocked both the number of tubules and interconnections formed by corneal fibroblasts cultured on Matrigel loaded with growth factors (90). IGF-1 is also critical in the process of keratocyte differentiation. During inflammation and wounding, stromal cells become activated and induce a differentiation program. Using a co-culture model, Ko et al. showed that both Simian virus 40-transformed human corneal epithelial cells (HCE) and primary cultured corneal fibroblasts secrete IGF-1 (91). Using siRNA knockdown of IGF1 in HCEs, they further demonstrated that IGF-1 secreted by corneal epithelial cells induces $\mathrm{N}$-cadherin expression, an adherens junction protein, in cultured corneal fibroblasts and that this was most likely regulated by the zinc finger protein, ZEB1. Unlike cancer cells, where the upregulation of $\mathrm{N}$ cadherin is associated with downregulation of E-cadherin and the subsequent epithelial-mesenchymal transition, the increase in $\mathrm{N}$ cadherin in corneal fibroblasts was not associated with changes in any other junctional proteins.
IGF-1 has also been shown to modulate the TGF-beta/SMAD signaling pathway, although the data is conflicting. Sarenac demonstrated that treatment of keratocytes with IGF-1 inhibited differentiation into myofibroblasts by attenuating TGF-beta signaling (92). They concluded that IGF-1 may be a viable therapeutic option to limit fibrosis during corneal wound healing. In contrast to this, Izumi found that IGF-1 stimulated proliferation of myofibroblasts during wound healing without first reverting cells back to their naïve state (93). This increased proliferation of myofibroblasts would further promote fibrosis. Taken together, these findings suggest that IGF-1 may induce differential effects on stromal cells depending on their differentiation status.

\section{IGF-2 IN STROMAL KERATOCYTES}

IGF-2 has been shown to play a key role in development of the murine eye (94). The function of IGF-2 has also been investigated in postnatal corneal development. To accomplish this, Kane et al. used keratocytes harvested from bovine and rabbit corneas (95). They measured collagen production and secretion of IGF-2 and IGFBP-2. Striking differences were noted. Rabbit keratocytes, which were proliferative in culture, secreted both Type I collagen and IGF-2. In contrast, bovine keratocytes, secreted IGFBP-2 and not IGF-2. Culture of bovine keratocytes in conditioned media from rabbit keratocytes promoted proliferation and collagen deposition, suggesting that IGF-2 is important in collagen production. Using microarrays, gene expression was next evaluated in keratocytes obtained from mouse neonates and compared to adults. IGF-2 was the most abundant growth factor present. IGF-I and IGFBP-4 were also detected, but were expressed at much lower levels. Interestingly, prior work by this same group showed that IGF-2 was present in the bovine stroma, despite not being secreted by bovine keratocytes (96). They further demonstrated that IGF-2 was capable of inducing keratocyte proliferation without inducing myofibroblasts differentiation. While the source of IGF-2 in the bovine stroma was not determined, IGF-2 appears to be integral to early stromal development.

\section{IGF-1 AND THE CORNEAL ENDOTHELIUM}

There has been limited research done on the role of IGF-1 in the corneal endothelium. In embryonic corneal tissue, IGF1 has been shown to promote DNA synthesis in endothelial cells $(97,98)$. Feldman and colleagues later used adult bovine corneal endothelium to test the effects of IGF-1 and insulin on DNA synthesis (78). Using BrdU labeling, they found that insulin and IGF-1 were both able to promote DNA synthesis. While both ligands were effective, insulin required much higher concentrations than IGF-1. This was due to the reduced affinity of insulin for IGF-1R. Another study evaluated the effects of IGF-1 on rabbit endothelial cells. In this study, Choi showed that IGF-1 promotes rabbit endothelial cell proliferation through the IRS-1 pathway (99). IGF-1 did not alter collagen production by these cells. Moreover, IGFBP-2 was produced by rabbit endothelial 
cells and functioned to sequester IGF-1. It is important to note however, that corneal endothelial cells do not undergo regeneration in vivo in cats, non-human primates, or humans. Thus, while IGF-1 promotes DNA synthesis and proliferation on corneal endothelial cells capable of mitosis, the effect of IGF-1 on the human corneal endothelium is relatively unknown.

\section{IGFBPs}

IGF-1 and IGF-2 are secreted into the extracellular environment where they are bound to IGFBPs (100). Currently, there are six highly conserved IGFBPs. IGFBPs are found in serum and most extracellular fluids, including the aqueous humor and vitreous $(101,102)$. Due to the presence of the blood-retinal barrier, the origins of these binding proteins are thought to be tissues within the eye. Several groups have probed for the presence of IGFBP-3 in ocular tissues. Most of these studies have focused on the localization of IGFBP mRNAs. Arnold et al. were the first to investigate the distribution of the IGFBPs in the eye. Using northern blotting, they reported that mRNAs for IGFBP2 and IGFBP- 3 were present in bovine corneas, but their exact distribution was not specified (101).

In the developing chick embryo, the appearance of IGFBP2 mRNA expression was found to be temporally and spatially controlled (103). Initially noted in the surface ectoderm at embryonic day 3.5 (E3.5), mRNA transcripts were detected in both the corneal epithelium and endothelium, as soon as the cornea began to develop into multilayers (E6). As development neared completion, IGFBP-2 transcripts were evident in all cells throughout the cornea. In a subsequent study, Burren and colleagues were able to confirm the presence of mRNA for IGFBP-2 in the cornea. In the rat eye, they found that IGFBP-2 localized to the basal layer of the corneal epithelium, keratocytes, and endothelium; however, they were unable to detect transcripts for any of the other binding proteins (104). More recently, expression of all six binding proteins was evaluated in a transgenic rat model that over-expressed the renin-2 gene (REN2). The REN-2 transgenic rat is a model for hypertension characterized by an alteration in the renin-angiotensin system that controls blood pressure (105). Type 1 diabetes was induced in this model using streptozotocin. The authors reported that transcripts for IGFBP-1, IGFBP-5, and IGFBP-6 were present in the cornea, with IGFBP- 5 and -6 found to be expressed at the protein level throughout the cornea, including the corneal epithelium. Moreover, transcript levels for these two binding proteins were altered in diabetes, with IGFBP-5 levels increasing and IGFBP-6 levels decreasing.

\section{IGFBP-2 AND STROMAL FIBROBLAST DIFFERENTIATION}

IGFBP-2 has been found to have an important role in mediating differentiation of corneal fibroblasts (102). In this study, the authors demonstrated that human corneal keratocytes express high levels of IGFBP-2. In corneal fibroblasts cultured on plastic, increased levels of IGFBP-2 were associated with increased expression of aldehyde dehydrogenase (ALDH1A1) and keratocan, markers for quiescent keratocytes. In contrast, keratocytes cultured on plastic and treated with TGF $\beta$ transformed into myofibroblasts and expressed high levels of $\alpha$-smooth muscle actin ( $\alpha$-SMA) and very low levels of IGFBP-2. This finding is consistent with the observation that TGF $\beta$ downregulates IGFBP-3 in dermal keratinocytes (106). Importantly, co-treatment of myofibroblasts with IGFBP-2 partially blocked this transformation through an increase in ALDH1A1, keratocan, and a partial loss of stress fibers, while siRNA knockdown of IGFBP-2 increased $\alpha$ SMA. Collectively, these data indicate that IGFBP-2 may be a crucial protein that regulates the sequential transition of keratocytes into fibroblasts and myofibroblasts and provide further support of a critical role for the IGF system in corneal wound healing.

\section{IGFBP-2 AND PTERYGIUM}

Recent data has shown a link between IGFBP-2 and human malignancies including prostate, ovarian, and colon cancer (107-109). Similarly, IGFBP-2 has been linked to pathological processes in the cornea. Pterygium, a non-cancerous conjunctival overgrowth onto the cornea, is known to express cellular markers that reflect increased proliferation and cellular invasion. Using cDNA microarrays, IGFBP-2 expression was increased in fibroblasts cultured from the pterygium body compared to conjunctival fibroblasts collected from normal tissue (110). In contrast, there were no differences in IGFBP-3 expression. This finding was confirmed at the protein level and suggests that aberrant IGFBP-2 expression may play a role in the development of pterygium.

\section{IGFBP-3}

Unlike IGFBP-2, IGFBP-3 is highly regulated at the posttranslational level by glycosylation and phosphorylation (111, 112). These post-translational modifications are hypothesized to regulate IGFBP-3s stability and function. In addition, IGFPB3 is also regulated by synthesis rate and extensive proteolysis $(113,114)$. Many tissues produce IGFBP-3 locally, where it plays an important role in growth inhibition, including the corneal epithelium $(10,115,116)$. IGFBP-3 has also been described as marker for senescence in cancer and in human fibroblasts $(117,118)$.

In dermal keratinocytes, IGFBP-3 has been shown to function as the main binding protein that interacts with IGF-1 to modulate proliferation (106). Consistent with this, altered expression of IGFBP-3 is associated with the development of psoriatic lesions (119). Izumi and colleagues used human corneal fibroblasts to show that treatment with TGF $\beta$ to induce $\alpha$-SMA expression also upregulated IGF-1 and IGFBP-3 mRNA (93). As already discussed, the increase in IGF-1 has multiple effects including an increase in myofibroblast proliferation and stimulation of collagen production. Prolonged proliferation of myofibroblasts would contribute to excess fibrosis. IGFBP- 3 on the other 
hand, modulates proliferation of myofibroblasts in an IGFdependent manner. In the mouse cornea in vivo, following photorefractive keratectomy, IGFBP-3 was upregulated and expressed throughout the corneal stroma (93). IGFBP-3 has been shown to bind to certain extracellular matrix proteins and once bound, may alter its affinity for IGF-1. Thus, a potential temporal or spatial gradient in IGF-1 and IGFBP-3 may regulate the degree of fibrosis during corneal wound healing.

More recently, work by our laboratory has begun investigating the role of IGFBP-3 in mediating stress responses in the corneal epithelium. We have shown that IGFBP-3 is upregulated during growth factor withdrawal. This increase in IGFBP-3 is necessary to induce nuclear translocation of Hybrid-R (10). Once in the nucleus, IGF-1R and IGFBP-3 accumulate in the insoluble fraction (10). IGFPB-3 does harbor a nuclear localization sequence and has been shown to traffic to the nucleus in other cell lines and tissues (120). Most available data suggests that nuclear localization is important in regulating apoptosis. The function of nuclear IGFBP-3 in the cornea is unknown.

While IGFBP-3 is necessary to induce trafficking of IGF$1 \mathrm{R}$, loss of IGF-1R in turn downregulates IGFBP-3. Thus, IGFBP-3 and IGF-1R undergo mutual regulation to maintain homeostasis in the corneal epithelium (10). We have also found that IGFBP-3 secretion is increased in response to hypoxia (unpublished observations), and in response to hyperglycemia (89). In agreement with this latter finding, we have reported that human tear levels of IGFBP-3 are similarly increased in patients with diabetes (121). More importantly, the increase in tear levels of IGFBP-3 in Type 2 diabetes correlates with damage to the corneal subbasal nerve plexus (Figure 5) (121). What remains unknown is the size of IGFBP-3 present in human tear fluid and whether this is the full-length glycosylated protein or a smaller cleavage fragment.

\section{SUMMARY AND FUTURE DIRECTIONS}

The IGF family is responsible for maintaining tissue homeostasis through the regulation of metabolic and/or mitogenic pathways at all cellular levels in the cornea. In addition to their canonical pathways, recent studies have led to the discovery of important intracellular functions in the corneal epithelium. This includes the nuclear translocation of Hybrid-R to the nuclei of human corneal epithelial cells in an IGF-1 independent manner and the ability of Hybrid-R to bind DNA and modulate gene expression. INSR and IGF-1R are also present in mitochondria where they likewise accumulate in the absence of IGF-1. The interaction of IGF-1R and INSR with VDAC1, a protein present in the outer mitochondrial membrane, suggests novel regulatory functions including the trafficking of molecules and ions, mitochondrial stability, and apoptosis. Further interrogation of these interactions may lead to the identification of critical new regulatory mechanism(s) that mediate mitochondrial function and quality control in the cornea and elsewhere in the body. These exciting new findings may also lead to the development of new therapeutic targets aimed at mitigating or preventing complications in patients with diabetes, where mitochondrial dysfunction is a central feature in the pathophysiology of disease.

One of the interesting characteristics that makes the corneal epithelium distinct from other epithelial tissues is the finding that insulin is not required for glucose uptake. Given the avascularity of the cornea, this is not altogether surprising. Insulin does have important regulatory roles in proliferation and cell growth in the corneal epithelium. These findings are not restricted to cell cultures in vitro, but extend to animal models and human studies. In diabetes, topical insulin does promote wound healing. The ability of insulin to restore circadian rhythm through $B M A L 1$ and CLOCK genes may facilitate re-epithelialization, as these rhythms may be disturbed in diabetes. One advantage of insulin compared to IGF-1 as a therapeutic option is that IGF1 is a potent inducer of angiogenesis. While insulin does have angiogenic capabilities, it is not clear from the limited clinical data whether the development of neovascularization from topical use will develop.

In the last few years, several studies have focused on elucidating non-glucose transport functions for insulin. The most recent findings from our laboratory have demonstrated roles for insulin in the regulation of metabolic homeostasis through control of mitochondrial respiration, glycolysis, and autophagy. We have further shown that insulin regulates
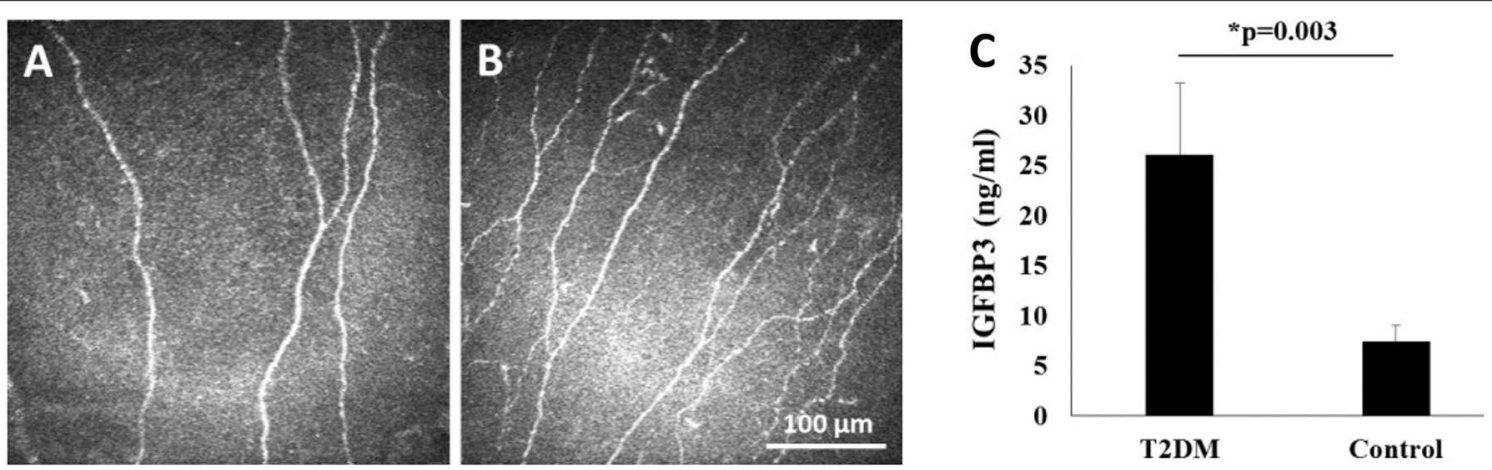

FIGURE 5 | Human tear levels of IGFBP-3 correlate with loss of the subbasal nerve plexus in T2DM. (A,B) In vivo confocal microscopy of the corneal subbasal nerve plexus showing (A) fewer corneal nerve fibers and branches in T2DM; and (B) normal nerve morphology in the healthy, non-diabetic control. Scale bar: $100 \mu m$. (C) Tear level of IGFBP-3 were increased in patients with T2DM compared to healthy controls ( $P=0.003$, $t$-test). Adapted from Stuard et al. (121). 
secretion of IGFBP-3, which in turn, mediates intracellular receptor trafficking. Interestingly, IGFBP-3 secretion is also mediated in part by IGF-1R. Taken together, these findings highlight the crosstalk that occurs between all the components of the IGF system. While the potential presence of proteases that further regulate IGF-1 bioavailability has not yet been investigated, it is clear that there is a delicate balance between members of the IGF-1 family that is critical for normal corneal development and tissue maintenance. Available evidence suggests that this balance is disrupted in diabetes and may contribute in part to recalcitrant wound healing. Moreover, since most of this work has been done in corneal epithelia, the role of insulin in keratocyte and endothelial health is relatively unknown and represents an important area of future study.

IGFBP-3 is a pleiotropic protein whose function is cell and context specific. Based on our prior studies, we hypothesize that IGFBP-3 functions as a major stress response protein in the corneal epithelium. In support of this view, tear levels of IGFBP-3 are increased in patients with diabetes and this increase correlates with loss of the subbasal nerve plexus. Much remains to be done to determine whether or not this discovery will lead to a novel diagnostic test that can be used to monitor patients with diabetes to determine potential risk for neuropathic or ocular complications. The advantages of using tears to monitor patients with diabetes include the ease and the relatively non-invasive nature of collection compared to phlebotomy. However, studies are needed to evaluate the impact of reflex tearing and dry eye on tear levels of IGFBP-3, and to determine its sensitivity and specificity compared to hemoglobin Alc.

In terms of wound healing, the major challenge facing clinicians today is fibrosis. While fibrosis may be disfiguring in

\section{REFERENCES}

1. Polisetti N, McLaughlin CR, Vemuganti GK, Griffith M. BiomaterialsEnabled Regenerative Medicine in Corneal Applications. Dordrecht: Springer (2013). doi: 10.1007/978-94-007-5690-8_22

2. Cai D, Zhu M, Petroll WM, Koppaka V, Robertson DM. The impact of type 1 diabetes mellitus on corneal epithelial nerve morphology and the corneal epithelium. Am J Pathol. (2014) 184:2662-70. doi: 10.1016/j.ajpath.2014.06.016

3. Matsumoto Y, Dogru M, Goto E, Ohashi Y, Kojima T, Ishida R, et al. Autologous serum application in the treatment of neurotrophic keratopathy. Ophthalmology. (2004) 111:1115-20. doi: 10.1016/j.ophtha.2003.10.019

4. Al-Aqaba MA, Dhillon VK, Mohammed I, Said DG, Dua HS. Corneal nerves in health and disease. Progr Ret Eye Res. (2019) 73:100762. doi: 10.1016/j.preteyeres.2019.05.003

5. Shih KC, Lam KSL, Tong L. A systematic review on the impact of diabetes mellitus on the ocular surface. Nutr Diabet. (2017) 7:e251. doi: $10.1038 /$ nutd.2017.4

6. Stapleton F, Alves M, Bunya VY, Jalbert I, Lekhanont K, Malet F, et al. TFOS DEWS II epidemiology report. Ocular Surface. (2017) 15:334-65. doi: 10.1016/j.jtos.2017.05.003

7. Bussan KA, Robertson DM. Contact lens wear and the diabetic corneal epithelium: a happy or disastrous marriage? J Diabetes Complicat. (2019) 33:75-83. doi: 10.1016/j.jdiacomp.2018.09.015

8. Conover CA, Oxvig C. PAPP-A: a promising therapeutic target for healthy longevity. Aging Cell. (2017) 16:205-9. doi: 10.1111/acel.12564 skin, it is a leading cause of blindness in the cornea. In severe cases, fibrosis necessitates full thickness corneal grafts to restore vision. There is a growing body of evidence to indicate that IGF family members play an important role in fibrosis. This includes regulating the differentiation of keratocytes into fibroblasts and myofibroblasts and the induction of myofibroblast proliferation without reverting cells back to a fibroblastic phenotype. Much more data is needed to fully understand the contribution of this system to wound healing, the critical crosstalk amongst the differing cell layers in the cornea, and corneal development.

In conclusion, a new outline regarding the impact of IGF family members on the cornea is beginning to emerge. Huge gaps in knowledge persist, creating multiple new areas of much needed research. Future studies will not only allow us to fill in these gaps, but will also allow us to gain a greater appreciation for the function of insulin, IGF, related binding proteins, and proteases, in the normal cornea and in disease.

\section{AUTHOR CONTRIBUTIONS}

WS and RT wrote the manuscript. DR wrote and edited the manuscript.

\section{FUNDING}

NIH/NEI R01 EY024546 (DR), R01 EY029258 (DR), P30 EY030413 (DR), A Fight for Sight Postdoctoral Fellowship (RT), and an unrestricted grant from Research to Prevent Blindness, New York, NY. The funders had no role in the development/writing of this manuscript.
9. Argente J, Chowen JA, Perez-Jurado LA, Frystyk J, Oxvig C. One level up: abnormal proteolytic regulation of IGF activity plays a role in human pathophysiology. EMBO Mol Med. (2017) 9:1338-45. doi: 10.15252/emmm.201707950

10. Titone R, Zhu M, Robertson DM. Mutual regulation between IGF-1R and IGFBP-3 in human corneal epithelial cells. J Cell Physiol. (2019) 234:1426-41. doi: $10.1002 /$ jcp. 26948

11. Titone $\mathrm{R}$, Zhu $\mathrm{M}$, Robertson $\mathrm{DM}$. Insulin mediates de novo nuclear accumulation of the IGF-1/insulin Hybrid Receptor in corneal epithelial cells. Sci Rep. (2018) 8:4378. doi: 10.1038/s41598-01821031-7

12. Vincent AM, Feldman EL. Control of cell survival by IGF signaling pathways. Growth Hormone IGF Res. (2002) 12:193-7. doi: 10.1016/S1096-6374(02)00017-5

13. LeRoith D, Werner H, Beitner-Johnson D, Roberts CT Jr. Molecular and cellular aspects of the insulin-like growth factor I receptor. Endocrine Rev. (1995) 16:143-63. doi: 10.1210/edrv-16-2-143

14. Ghosh P, Dahms NM, Kornfeld S. Mannose 6-phosphate receptors: new twists in the tale. Nat Rev. (2003) 4:202-12. doi: 10.1038/nrm1050

15. Naeser P. Insulin receptors in human ocular tissues. Immunohistochemical demonstration in normal and diabetic eyes. Upsala J Med Sci. (1997) 102:3540. doi: 10.3109/03009739709178930

16. Rocha EM, Cunha DA, Carneiro EM, Boschero AC, Saad MJA, Velloso LA. Identification of insulin in the tear film and insulin receptor and IGF-1 receptor on the human ocular surface. Invest Ophthalmol Vis Sci. (2002) 43:963-7. 
17. Nakamura M, Chikama TI, Nishida T. Characterization of insulin-like growth factor-1 receptors in rabbit corneal epithelial cells. Exp Eye Res. (2000) 70:199-204. doi: 10.1006/exer.1999.0775

18. Robertson DM, Zhu M, Wu YC. Cellular distribution of the IGF1R in corneal epithelial cells. Exp Eye Res. (2012) 94:179-86. doi: 10.1016/j.exer.2011.12.006

19. Wu YC, Zhu M, Robertson DM. Novel nuclear localization and potential function of insulin-like growth factor-1 receptor/insulin receptor hybrid in corneal epithelial cells. PLoS ONE. (2012) 7:e42483. doi: 10.1371/journal.pone.0042483

20. Qian X, Karpova T, Sheppard AM, McNally J, Lowy DR. E-cadherinmediated adhesion inhibits ligand-dependent activation of diverse receptor tyrosine kinases. EMBO J. (2004) 23:1739-48. doi: 10.1038/sj.emboj.7600136

21. Mauro L, Salerno M, Morelli C, Boterberg T, Bracke ME, Surmacz E. Role of the IGF-I receptor in the regulation of cell-cell adhesion: implications in cancer development and progression. J Cell Physiol. (2003) 194:108-16. doi: $10.1002 /$ jcp. 10207

22. De Meyts P, Whittaker J. Structural biology of insulin and IGF1 receptors: implications for drug design. Nat Rev. (2002) 1:769-83. doi: 10.1038/nrd917

23. Bohnsack RN, Warejcka DJ, Wang L, Gillespie SR, Bernstein AM, Twining SS, et al. Expression of insulin-like growth factor 2 receptor in corneal keratocytes during differentiation and in response to wound healing. Invest Ophthalmol Vis Sci. (2014) 55:7697-708. doi: 10.1167/iovs.1415179

24. Sarfstein R, Werner H. Minireview: nuclear insulin and insulin-like growth factor-1 receptors: a novel paradigm in signal transduction. Endocrinology. (2013) 154:1672-9. doi: 10.1210/en.2012-2165

25. Sehat B, Tofigh A, Lin Y, Trocme E, Liljedahl U, Lagergren J, et al. SUMOylation mediates the nuclear translocation and signaling of the IGF-1 receptor. Sci Signal. (2010) 3:ra10. doi: 10.1126/scisignal.2000628

26. Warsito D, Sjostrom S, Andersson S, Larsson O, Sehat B. Nuclear IGF1R is a transcriptional co-activator of LEF1/TCF. EMBO Rep. (2012) 13:244-50. doi: 10.1038/embor.2011.251

27. Deng H, Lin Y, Badin M, Vasilcanu D, Stromberg T, Jernberg-Wiklund $\mathrm{H}$, et al. Over-accumulation of nuclear IGF-1 receptor in tumor cells requires elevated expression of the receptor and the SUMOconjugating enzyme Ubc9. Biochem Biophys Res Commun. (2011) 404:66771. doi: 10.1016/j.bbrc.2010.12.038

28. Warsito D, Lin Y, Gnirck AC, Sehat B, Larsson O. Nuclearly translocated insulin-like growth factor 1 receptor phosphorylates histone $\mathrm{H} 3$ at tyrosine 41 and induces SNAI2 expression via Brg1 chromatin remodeling protein. Oncotarget. (2016) 7:42288-302. doi: 10.18632/oncotarget. 9785

29. Waraky A, Lin Y, Warsito D, Haglund F, Aleem E, Larsson O. Nuclear insulin-like growth factor 1 receptor phosphorylates proliferating cell nuclear antigen and rescues stalled replication forks after DNA damage. $J$ Biol Chem. (2017) 292:18227-39. doi: 10.1074/jbc.M117.781492

30. Goldfine ID, Smith GJ. Binding of insulin to isolated nuclei. Proc Natl Acad Sci USA. (1976) 73:1427-31. doi: 10.1073/pnas.73.5.1427

31. Soler AP, Thompson KA, Smith RM, Jarett L. Immunological demonstration of the accumulation of insulin, but not insulin receptors, in nuclei of insulin-treated cells. Proc Natl Acad Sci USA. (1989) 86:6640-4. doi: 10.1073/pnas.86.17.6640

32. Rodrigues MA, Gomes DA, Andrade VA, Leite MF, Nathanson MH. Insulin induces calcium signals in the nucleus of rat hepatocytes. Hepatology. (2008) 48:1621-31. doi: 10.1002/hep.22424

33. Hancock ML, Meyer RC, Mistry M, Khetani RS, Wagschal A, Shin T, et al. Insulin receptor associates with promoters genome-wide and regulates gene expression. Cell. (2019) 177:722-36. doi: 10.1016/j.cell.2019.02.030

34. Titone R, Robertson DM. Insulin receptor preserves mitochondrial function by binding VDAC1 in insulin insensitive mucosal epithelial cells. FASEB J. (2019) 34:754-75. doi: 10.1096/fj.201901316RR

35. De Meyts P. Insulin and its receptor: structure, function, and evolution. Bioessays. (2004) 26:1351-62. doi: 10.1002/bies.20151

36. Blundell TL, Cutfield JF, Cutfield SM, Dodson EJ, Dodson GG, Hodgkin DC, et al. Three-dimensional atomic structure of insulin and its relationship to activity. Diabetes. (1972) 21:492-505. doi: 10.2337/diab.21.2.S492
37. Steiner DF, Clark JL, Nolan C, Rubenstein AH, Margoliash E, Aten B, et al. Proinsulin and the biosynthesis of insulin. Recent Prog Horm Res. (1969) 25:207-82. doi: 10.1016/B978-0-12-571125-8.50008-9

38. Huang S, Czech MP. The GLUT4 glucose transporter. Cell Metab. (2007) 5:237-52. doi: 10.1016/j.cmet.2007.03.006

39. Friend J, Snip RC, Kiorpes TC, Thoft RA. Insulin sensitivity and sorbitol production of the normal rabbit corneal epithelium in vitro. Invest Ophthalmol Vis Sci. (1980) 19:913-9.

40. Cunha DA, Carneiro EM, Alves Mde C, Jorge AG, de Sousa SM, Boschero AC, et al. Insulin secretion by rat lacrimal glands: effects of systemic and local variables. Am J Physiol. (2005) 289:E768-75. doi: 10.1152/ajpendo.00469.2004

41. Mueckler M. Family of glucose-transporter genes. Implications for glucose homeostasis and diabetes. Diabetes. (1990) 39:6-11. doi: 10.2337/diabetes.39.1.6

42. Takahashi H, Kaminski AE, Zieske JD. Glucose transporter 1 expression is enhanced during corneal epithelial wound repair. Exp Eye Res. (1996) 63:649-59. doi: 10.1006/exer.1996.0159

43. Takahashi H, Ohara K, Ohmura T, Takahashi R, Zieske JD. Glucose transporter 1 expression in corneal wound repair under high serum glucose level. Jpn J Ophthalmol. (2000) 44:470-4. doi: 10.1016/S0021-5155(00)00222-7

44. Kumagai AK, Glasgow BJ, Pardridge WM. GLUT1 glucose transporter expression in the diabetic and non-diabetic human eye. Invest Ophthalmol Vis Sci. (1994) 35:2887-94.

45. White MF, White MF. Mechanisms of insulin action. In: Skyler J, editor. Atlas of Diabetes. 4th ed. Boston, MA: Springer US (2012). p. 19-38. doi: 10.1007/978-1-4614-1028-7_2

46. Laplante M, Sabatini DM. mTOR signaling at a glance. J Cell Sci. (2009) 122:3589-94. doi: 10.1242/jcs.051011

47. Lin CF, Chen CL, Chiang CW, Jan MS, Huang WC, Lin YS. GSK-3beta acts downstream of PP2A and the PI 3-kinase-Akt pathway, and upstream of caspase-2 in ceramide-induced mitochondrial apoptosis. J Cell Sci. (2007) 120:2935-43. doi: 10.1242/jcs.03473

48. Yang K, Chen Z, Gao J, Shi W, Li L, Jiang S, et al. The key roles of GSK-3beta in regulating mitochondrial activity. Cell Physiol Biochem. (2017) 44:1445-59. doi: 10.1159/000485580

49. De Duve C, Wattiaux R. Functions of lysosomes. Annu Rev Physiol. (1966) 28:435-92. doi: 10.1146/annurev.ph.28.030166.002251

50. Sprenger HG, Langer T. The good and the bad of mitochondrial breakups. Trends Cell Biol. (2019) 29:888-900. doi: 10.1016/j.tcb.2019.08.003

51. Lyons A, Coleman M, Riis S, Favre C, O'Flanagan CH, Zhdanov AV, et al. Insulin-like growth factor 1 signaling is essential for mitochondrial biogenesis and mitophagy in cancer cells. J Biol Chem. (2017) 292:16983-98. doi: 10.1074/jbc.M117.792838

52. Xu KP, Li Y, Ljubimov AV, Yu FS. High glucose suppresses epidermal growth factor receptor/phosphatidylinositol 3-kinase/Akt signaling pathway and attenuates corneal epithelial wound healing. Diabetes. (2009) 58:1077-85. doi: $10.2337 / \mathrm{db} 08-0997$

53. Zhu L, Titone R, Robertson DM. The impact of hyperglycemia on the corneal epithelium: molecular mechanisms and insight. Ocul Surf. (2019) 17:644-54. doi: 10.1016/j.jtos.2019.06.007

54. Ljubimov AV. Diabetic complications in the cornea. Vision Res. (2017) 139:138-52. doi: 10.1016/j.visres.2017.03.002

55. Zagon IS, Klocek MS, Sassani JW, McLaughlin PJ. Use of topical insulin to normalize corneal epithelial healing in diabetes mellitus. Archiv Ophthalmol. (2007) 125:1082-8. doi: 10.1001/archopht.125.8.1082

56. Bastion ML, Ling KP. Topical insulin for healing of diabetic epithelial defects?: a retrospective review of corneal debridement during vitreoretinal surgery in Malaysian patients. Med J Malaysia. (2013) 68:208-16.

57. Fai S, Ahem A, Mustapha M, Mohd Noh UK, Bastion MC. Randomized controlled trial of topical insulin for healing corneal epithelial defects induced during vitreoretinal surgery in diabetics. Asia-Pacific J Ophthalmol. (2017) 6:418-24. doi: 10.22608/apo.201780

58. Song F, Xue Y, Dong D, Liu J, Fu T, Xiao C, et al. Insulin restores an altered corneal epithelium circadian rhythm in mice with streptozotocin-induced type 1 diabetes. Sci Rep. (2016) 6:32871. doi: 10.1038/srep32871 
59. Wang AL, Weinlander E, Metcalf BM, Barney NP, Gamm DM, Nehls $\mathrm{SM}$, et al. Use of topical insulin to treat refractory neurotrophic corneal ulcers. Cornea. (2017) 36:1426-8. doi: 10.1097/ICO.0000000000 001297

60. Nishida T, Nakamura M, Ofuji K, Reid TW, Mannis MJ, Murphy CJ. Synergistic effects of substance $\mathrm{P}$ with insulin-like growth factor-1 on epithelial migration of the cornea. J Cell Physiol. (1996) 169:159-66. doi: 10. 1002/(SICI)1097-4652(199610)169:1<159::AID-JCP16>3.0.CO;2-8

61. Chikama T, Nakamura M, Nishida T. Up-regulation of integrin $\alpha 5$ by a Cterminus four-amino-acid sequence of substance $\mathrm{P}$ (phenylalanine-glycineleucine-methionine-amide) synergistically with insulin-like growth factor-1 in SV-40 transformed human corneal epithelial cells. Biochem Biophys Res Commun. (1999) 255:692-7. doi: 10.1006/bbrc.1999.0267

62. Nakamura M, Ofuji K, Chikama T, Nishida T. Combined effects of substance $\mathrm{P}$ and insulin-like growth factor-1 on corneal epithelial wound closure of rabbit in vivo. Curr Eye Res. (1997) 16:275-8. doi: 10.1076/ceyr.16.3.275.15409

63. Nakamura M, Chikama T, Nishida T. Synergistic effect with Phe-Gly-LeuMet-NH2 of the C-terminal of substance $\mathrm{P}$ and insulin-like growth factor1 on epithelial wound healing of rabbit cornea. Br J Pharmacol. (1999) 127:489-97. doi: 10.1038/sj.bjp.0702550

64. Nagano T, Nakamura M, Nakata K, Yamaguchi T, Takase K, Okahara A, et al. Effects of substance P and IGF-1 in corneal epithelial barrier function and wound healing in a rat model of neurotrophic keratopathy. Invest Ophthalmol Vis Sci. (2003) 44:3810-5. doi: 10.1167/iovs.03-0189

65. Nakamura M, Kawahara M, Nakata K, Nishida T. Restoration of corneal epithelial barrier function and wound healing by substance P and IGF-1 in rats with capsaicin-induced neurotrophic keratopathy. Invest Ophthalmol Vis Sci. (2003) 44:2937-40. doi: 10.1167/iovs.02-0868

66. Nakamura M, Kawahara M, Morishige N, Chikama T, Nakata K, Nishida T. Promotion of corneal epithelial wound healing in diabetic rats by the combination of a substance P-derived peptide (FGLMNH2) and insulin-like growth factor-1. Diabetologia. (2003) 46:839-42. doi: 10.1007/s00125-003-1105-9

67. Yamada N, Yanai R, Nakamura M, Inui M, Nishida T. Role of the C domain of IGFs in synergistic promotion, with a substance P-derived peptide, of rabbit corneal epithelial wound healing. Invest Ophthalmol Vis Sci. (2004) 45:1125-31. doi: 10.1167/iovs.03-0626

68. Lee HK, Lee JH, Kim M, Kariya Y, Miyazaki K, Kim EK. Insulin-like growth factor-1 induces migration and expression of laminin-5 in cultured human corneal epithelial cells. Invest Ophthalmol Vis Sci. (2006) 47:873-82. doi: 10.1167/iovs.05-0826

69. Nishida T, Chikama T, Morishige N, Yanai R, Yamada N, Saito J. Persistent epithelial defects due to neurotrophic keratopathy treated with a substance p-derived peptide and insulin-like growth factor 1. Jpn J Ophthalmol. (2007) 51:442-7. doi: 10.1007/s10384-007-0480-z

70. Yamada N, Matsuda R, Morishige N, Yanai R, Chikama TI, Nishida $\mathrm{T}$, et al. Open clinical study of eye-drops containing tetrapeptides derived from substance $\mathrm{P}$ and insulin-like growth factor-1 for treatment of persistent corneal epithelial defects associated with neurotrophic keratopathy. Br J Ophthalmol. (2008) 92:896-900. doi: 10.1136/bjo.2007. 130013

71. Trosan P, Svobodova E, Chudickova M, Krulova M, Zajicova A, Holan V. The key role of insulin-like growth factor I in limbal stem cell differentiation and the corneal wound-healing process. Stem Cells Dev. (2012) 21:3341-50. doi: $10.1089 / \mathrm{scd} .2012 .0180$

72. Ghiasi Z, Gray T, Tran P, Dubielzig R, Murphy C, McCartney DL, et al. The effect of topical substance-P plus insulin-like growth factor-1 (IGF-1) on epithelial healing after photorefractive keratectomy in rabbits. Transl Vis Sci Technol. (2018) 7:12. doi: 10.1167/tvst.7.1.12

73. Jiang Y, Ju Z, Zhang J, Liu X, Tian J, Mu G. Effects of insulin-like growth factor 2 and its receptor expressions on corneal repair. Int J Clin Exp Pathol. (2015) 8:10185-91.

74. Xue Y, Liu P, Wang H, Xiao C, Lin C, Liu J, et al. Modulation of circadian rhythms affects corneal epithelium renewal and repair in mice. Invest Ophthalmol Vis Sci. (2017) 58:1865-74. doi: 10.1167/iovs.16-21154

75. Lavker RM, Dong G, Cheng SZ, Kudoh K, Cotsarelis G, Sun TT. Relative proliferative rates of limbal and corneal epithelia. Implications of corneal epithelial migration, circadian rhythm, and suprabasally located DNAsynthesizing keratinocytes. Invest Ophthalmol Vis Sci. (1991) 32:1864-75.

76. Kwarecki K, Krawczyk J. Comparison of the circadian rhythm in cell proliferation in corneal epithelium of male rats studied under normal and hypobaric (hypoxic) conditions. Chronobiol Int. (1989) 6:217-22. doi: 10.3109/07420528909056921

77. Scheving LE, Pauly JE. Circadian phase relationships of thymidine-3H uptake, labeled nuclei, grain counts, and cell division rate in rat corneal epithelium. J Cell Biol. (1967) 32:677-83. doi: 10.1083/jcb.32.3.677

78. Feldman ST, Gately D, Seely BL, Schonthal A, Feramisco JR. Stimulation of DNA synthesis and c-fos expression in corneal endothelium by insulin or insulin-like growth factor-I. Invest Ophthalmol Vis Sci. (1993) 34:2105-11.

79. Foulks GN, Thoft RA, Perry HD, Tolentino FI. Factors related to corneal epithelial complications after closed vitrectomy in diabetics. Archiv Ophthalmol. (1979) 97:1076-8. doi: 10.1001/archopht.1979.01020010530002

80. Herse PR. Corneal hydration control in normal and alloxan-induced diabetic rabbits. Invest Ophthalmol Vis Sci. (1990) 31:2205-13.

81. Hatou S, Yamada M, Akune Y, Mochizuki H, Shiraishi A, Joko T, et al. Role of insulin in regulation of $\mathrm{Na}+-/ \mathrm{K}+$-dependent ATPase activity and pump function in corneal endothelial cells. Invest Ophthalmol Vis Sci. (2010) 51:3935-42. doi: 10.1167/iovs.09-4027

82. Hatou S, Yamada M, Mochizuki H, Shiraishi A, Joko T, Nishida T. The effects of dexamethasone on the Na,K-ATPase activity and pump function of corneal endothelial cells. Curr Eye Res. (2009) 34:347-54. doi: 10.1080/02713680902829624

83. Baxter RC, Martin JL. Radioimmunoassay of growth hormone-dependent insulinlike growth factor binding protein in human plasma. J Clin Invest. (1986) 78:1504-12. doi: 10.1172/JCI112742

84. Favelyukis S, Till JH, Hubbard SR, Miller WT. Structure and autoregulation of the insulin-like growth factor 1 receptor kinase. Nat Struct Biol. (2001) 8:1058-63. doi: 10.1038/nsb721

85. Shelton JG, Steelman LS, White ER, McCubrey JA. Synergy between PI3K/Akt and Raf/MEK/ERK pathways in IGF-1R mediated cell cycle progression and prevention of apoptosis in hematopoietic cells. Cell Cycle. (2004) 3:372-9. doi: 10.4161/cc.3.3.747

86. Todorovic V, Pesko P, Micev M, Bjelovic M, Budec M, Micic M, et al. Insulinlike growth factor-I in wound healing of rat skin. Regul Peptides. (2008) 150:7-13. doi: 10.1016/j.regpep.2008.05.006

87. Nakamura M, Ofuji K, Chikama T, Nishida T. The NK1 receptor and its participation in the synergistic enhancement of corneal epithelial migration by substance P and insulin-like growth factor-1. Br J Pharmacol. (1997) 120:547-52. doi: 10.1038/sj.bjp.0700923

88. Patel R, Zhu M, Robertson DM. Shifting the IGF-axis: an age-related decline in human tear IGF-1 correlates with clinical signs of dry eye. Growth Hormone IGF Res. (2018) 40:69-73. doi: 10.1016/j.ghir.2018.02.001

89. Wu YC, Buckner BR, Zhu M, Cavanagh HD, Robertson DM. Elevated IGFBP3 levels in diabetic tears: a negative regulator of IGF-1 signaling in the corneal epithelium. Ocular Surface. (2012) 10:100-7. doi: 10.1016/j.jtos.2012.01.004

90. Berthaut A, Mirshahi P, Benabbou N, Ducros E, Agra A, Therwath $A$, et al. Insulin growth factor promotes human corneal fibroblast network formation in vitro. Invest Ophthalmol Vis Sci. (2011) 52:7647-53. doi: 10.1167/iovs.10-5625

91. Ko JA, Yanai R, Nishida T. IGF-1 released by corneal epithelial cells induces up-regulation of N-cadherin in corneal fibroblasts. J Cell Physiol. (2009) 221:254-61. doi: 10.1002/jcp.21850

92. Sarenac T, Trapecar M, Gradisnik L, Rupnik MS, Pahor D. Single-cell analysis reveals IGF- 1 potentiation of inhibition of the TGF- $\beta / \mathrm{Smad}$ pathway of fibrosis in human keratocytes in vitro. Sci Rep. (2016) 6:34373. doi: 10.1038/srep34373

93. Izumi K, Kurosaka D, Iwata T, Oguchi Y, Tanaka Y, Mashima Y, et al. Involvement of insulin-like growth factor-I and insulin-like growth factor binding protein-3 in corneal fibroblasts during corneal wound healing. Invest Ophthalmol Vis Sci. (2006) 47:591-8. doi: 10.1167/iovs. 05-0097

94. Cuthbertson RA, Beck F, Senior PV, Haralambidis J, Penschow JD, Coghlan JP. Insulin-like growth factor II may play a local role in the regulation of ocular size. Development. (1989) 107:123-30. 
95. Kane BP, Jester JV, Huang J, Wahlert A, Hassell JR. IGF-II and collagen expression by keratocytes during postnatal development. Exp Eye Res. (2009) 89:218-23. doi: 10.1016/j.exer.2009.03.010

96. Musselmann K, Kane BP, Alexandrou B, Hassell JR. IGF-II is present in bovine corneal stroma and activates keratocytes to proliferate in vitro. Exp Eye Res. (2008) 86:506-11. doi: 10.1016/j.exer.2007. 12.004

97. Hyldahl L. Control of cell proliferation in the human embryonic cornea: an autoradiographic analysis of the effect of growth factors on DNA synthesis in endothelial and stromal cells in organ culture and after explantation in vitro. J Cell Sci. (1986) 83:1-21.

98. Woost PG, Jumblatt MM, Eiferman RA, Schultz GS. Growth factors and corneal endothelial cells: I. Stimulation of bovine corneal endothelial cell DNA synthesis by defined growth factors. Cornea. (1992) 11:1-10. doi: 10.1097/00003226-199201000-00001

99. Choi SH, Kay EP, Oh DS, Gu X, Smith RE. Insulin-like growth factor-I promotes cell proliferation in the absence of modulation of collagen phenotypes and utilizes IRS-1, not PLC-gamma 1, in corneal endothelial cells. Curr Eye Res. (1995) 14:669-76. doi: 10.3109/02713689508 998494

100. Firth SM, Baxter RC. Cellular actions of the insulin-like growth factor binding proteins. Endocrine Rev. (2002) 23:824-54. doi: 10.1210/er.2001-0033

101. Arnold DR, Moshayedi P, Schoen TJ, Jones BE, Chader GJ, Waldbillig RJ. Distribution of IGF-I and -II, IGF binding proteins (IGFBPs) and IGFBP mRNA in ocular fluids and tissues: potential sites of synthesis of IGFBPs in aqueous and vitreous. Exp Eye Res. (1993) 56:555-65. doi: 10.1006/exer.1993.1069

102. Park SH, Kim KW, Kim JC. The role of insulin-like growth factor binding protein 2 (IGFBP2) in the regulation of corneal fibroblast differentiation. Invest Ophthalmol Vis Sci. (2015) 56:7293-302. doi: 10.1167/iovs.1516616

103. Schoen TJ, Bondy CA, Zhou J, Dhawan R, Mazuruk K, Arnold DR, et al. Differential temporal and spatial expression of insulin-like growth factor binding protein-2 in developing chick ocular tissues. Invest Ophthalmol Vis Sci. (1995) 36:2652-62.

104. Burren CP, Berka JL, Edmondson SR, Werther GA, Batch JA. Localization of mRNAs for insulin-like growth factor-I (IGF-I), IGF-I receptor, and IGF binding proteins in rat eye. Invest Ophthalmol Vis Sci. (1996) 37:1459-68.

105. Bergman PB, Moravski CJ, Edmondson SR, Russo VC, Bach LA, WilkinsonBerka JL, et al. Expression of the IGF system in normal and diabetic transgenic (mRen-2)27 rat eye. Invest Ophthalmol Vis Sci. (2005) 46:2708-15. doi: 10.1167/iovs.04-0921

106. Edmondson SR, Murashita MM, Russo VC, Wraight CJ, Werther GA. Expression of insulin-like growth factor binding protein3 (IGFBP-3) in human keratinocytes is regulated by EGF and TGFbeta1. J Cell Physiol. (1999) 179:201-7. doi: 10.1002/(SICI) 1097-4652(199905)179:2<201::AID-JCP10>3.0.CO;2-9

107. Flyvbjerg A, Mogensen O, Mogensen B, Nielsen OS. Elevated serum insulinlike growth factor-binding protein 2 (IGFBP-2) and decreased IGFBP-3 in epithelial ovarian cancer: correlation with cancer antigen 125 and tumorassociated trypsin inhibitor. J Clin Endocrinol Metab. (1997) 82:2308-13. doi: 10.1210/jc.82.7.2308

108. El Atiq F, Garrouste F, Remacle-Bonnet M, Sastre B, Pommier G. Alterations in serum levels of insulin-like growth factorsand insulin-like growth-factor-binding proteins in patients with colorectal cancer. Int $J$ Cancer. (1994) 57:491. doi: 10.1002/ijc.2910570409

109. Ho PJ, Baxter RC. Insulin-like growth factor-binding protein-2 in patients with prostate carcinoma and benign prostatic hyperplasia. Clin Endocrinol. (1997) 46:145-54. doi: 10.1046/j.1365-2265.1997.1100922.x

110. Solomon A, Grueterich M, Li DQ, Meller D, Lee SB, Tseng SCG. Overexpression of insulin-like growth factor-binding protein-2 in pterygium body fibroblasts. Invest Ophthalmol Vis Sci. (2003) 44:573-80. doi: 10.1167/iovs.01-1185

111. Firth SM, Baxter RC. The role of glycosylation in the action of IGFBP-3. Progr Growth Factor Res. (1995) 6:223-9. doi: 10.1016/0955-2235(95)00009-7

112. Baxter RC, Firth SM. Modulation of human IGF binding protein-3 activity by structural modification. Progr Growth Factor Res. (1995) 6:215-22. doi: 10.1016/0955-2235(95)00004-6

113. Hughes SC, Xu S, Fernihough J, Hampton A, Mason HD, Franks $\mathrm{S}$, et al. Tissue IGFBP-3 proteolysis: contrasting pathophysiology to that in the circulation. Progr Growth Factor Res. (1995) 6:293-9. doi: 10.1016/0955-2235(96)00041-5

114. Baxter RC. Inhibition of the insulin-like growth factor (IGF)-IGFbinding protein interaction. Hormone Res. (2001) 55(Suppl. 2):68-72. doi: 10.1159/000063479

115. Baxter RC, Martin JL. Binding proteins for the insulin-like growth factors: structure, regulation, and function. Progr Growth Factor Res. (1989) 1:49-68. doi: 10.1016/0955-2235(89)90041-0

116. Baxter RC. Signalling pathways involved in antiproliferative effects of IGFBP-3: a review. Mol Pathol. (2001) 54:145-8. doi: 10.1136/mp.54.3.145

117. Hampel B, Wagner M, Teis D, Zwerschke W, Huber LA, Jansen-Durr P. Apoptosis resistance of senescent human fibroblasts is correlated with the absence of nuclear IGFBP-3. Aging Cell. (2005) 4:325-30. doi: 10.1111/j.1474-9726.2005.00180.x

118. Hong S, Kim MM. IGFBP-3 plays an important role in senescence as an aging marker. Environ Toxicol Pharmacol. (2018) 59:138-45. doi: 10.1016/j.etap.2018.03.014

119. Wraight CJ, Edmondson SR, Fortune DW, Varigos G, Werther GA. Expression of insulin-like growth factor binding protein-3 (IGFBP$3)$ in the psoriatic lesion. J Invest Dermatol. (1997) 108:452-6. doi: 10.1111/1523-1747.ep12289713

120. Baxter RC. Nuclear actions of insulin-like growth factor binding protein-3. Gene. (2015) 569:7-13. doi: 10.1016/j.gene.2015.06.028

121. Stuard WL, Titone R, Robertson DM. Tear levels of insulin-like growth factor binding protein 3 correlate with subbasal nerve plexus changes in patients with type 2 diabetes mellitus. Invest Ophthalmol Vis Sci. (2017) 58:6105-12. doi: $10.1167 /$ iovs.17-22425

Conflict of Interest: The authors declare that the research was conducted in the absence of any commercial or financial relationships that could be construed as a potential conflict of interest.

Copyright (c) 2020 Stuard, Titone and Robertson. This is an open-access article distributed under the terms of the Creative Commons Attribution License (CC BY). The use, distribution or reproduction in other forums is permitted, provided the original author(s) and the copyright owner(s) are credited and that the original publication in this journal is cited, in accordance with accepted academic practice. No use, distribution or reproduction is permitted which does not comply with these terms. 